Revista de la red interuniversitaria de estudios sobre las literaturas rioplatenses contemporáneas en Francia

$13 \mid 2015$

Nuevas experiencias editoriales y literaturas

contemporáneas

\title{
Pero corre hacia las luciérnagas
}

Joaquín Correa

\section{OpenEdition}

\section{Journals}

Edición electrónica

URL: http://journals.openedition.org/lirico/2170

DOI: $10.4000 /$ lirico. 2170

ISSN: 2262-8339

Editor

Réseau interuniversitaire d'étude des littératures contemporaines du Río de la Plata

Referencia electrónica

Joaquín Correa, «Pero corre hacia las luciérnagas », Cuadernos LIRICO [En línea], 13 | 2015, Publicado el 01 enero 2016, consultado el 25 septiembre 2020. URL : http://journals.openedition.org/lirico/2170 ; DOI : https://doi.org/10.4000/lirico.2170

Este documento fue generado automáticamente el 25 septiembre 2020

\section{(c) (i) () $\Theta$}

Cuadernos LIRICO está distribuido bajo una Licencia Creative Commons Atribución-NoComercialSinDerivar 4.0 Internacional 


\title{
Pero corre hacia las luciérnagas
}

\author{
Joaquín Correa
}

\section{REFERENCIA}

Carrera, Arturo. Haikus de las cuatro estaciones. Buenos Aires : Interzona, 2013, 128 p.

1 "Devenir niño mediante la escritura es ir hacia una infancia del mundo, restaurar una infancia del mundo, ésa es una tarea, son las tareas de la literatura" aún nos sigue diciendo Gilles Deleuze desde la apertura de Las cuatro estaciones, texto que Arturo Carrera publicó en 2008 y que, de alguna forma, vuelve a presentarse en el último texto que lleva su nombre en la portada: Haikus de las cuatro estaciones. Porque esa infancia del mundo será buscada, ahora, en la contemplación que da origen a los haikus y que éstos a su vez ponen en escena en un tiempo fuera del tiempo, intempestivo y constante. En los trabajos de Bashô y sus discípulos esa tarea será parte del día a día y la escritura, un gesto más entre los tantos que pueden ir recogiéndose en la fuga de lo cotidiano.

2 Las "estaciones" del título, en el universo de Arturo, pueden asociarse, al menos, a dos movimientos, en principio contrarios: las estaciones del año desde donde surge, se enuncia o se manifiesta la "designación levísima" del haiku o las estaciones del ferrocarril, otrora signos del progreso y el avance de la civilización, hoy ruinas del desastre neoliberal. La distancia entre los homónimos se aproxima y es colmada por el lenguaje de la infancia. En ambos casos, las estaciones son recorridos, movimientos, ritmos y guardan en sí el espacio - tiempo de la utopía, de la utopía en lo cotidiano, de la micro-utopía.

3 El haiku es una escritura del afecto, del afectarse. En el prólogo, Arturo cita a Barthes, o mejor dicho : se re-apropia de sus palabras : "el haiku reproduce el gesto indicativo del niño pequeño que muestra con el dedo cualquier cosa (el haiku no tiene acepción de sujetos), diciendo tan solo : ¡ esto !, ¡ mirá allá !, j oh !, ¡ ah !” (Carrera 2013 9). Leemos la memoria del niño, su lenguaje, su sorpresa, sus gestos : en ese afecto ya no será Barthes quien nos hable sino la poética del propio Carrera, como no serán, tampoco, Bashô y sus 
discípulos a quienes encontraremos, impolutos, a continuación, sino a una sobrevida de aquellos escritores zen habitando la pampa pringlense.

XIX.

Desde la puerta vi a la abuela que venía como una marioneta con los hilos cortados y enredados; pero se movía, apenas, como si bailara. Daba unos aéreos pasitos cortos, inexpertos y cuidados. Temblaba entera ; gritaba ; y todo lo hacía como entre estallidos de platillos y címbalos que ella en un sueño dirigía.

Sacudía un pie, que le dolía. En la cara traía el mismo dolor y

la misma serenidad que un títere del bunraku.

El mismo gesto trágico de máscara que tensa en nosotros instantáneamente las cuerdas de una disonancia infinita que nos hace o llorar o reír.

El Coco la acercó a la silla. Una vez sentada, se tocaba la cara con una mano y agitaba la otra como un sonajero. $Y$ empezó a gritar otra vez, pero se le entendía todo : “... sé váaaaa, sé váaaa, sé váaaaa.." La miré a Guillermina y le dije : “¡Vamos !" Pero siguió : “Cé báaa... únos máates.” (Carrera 2003 31)

La descripción de los bunrakus fue hecha también por Barthes en aquel mismo texto del que Arturo toma la cita : El imperio de los signos. Y el movimiento, la acción, la praxis de la lectura se aproximan, también aquí : en el universo pringlense del Coco, lo oriental. Al revés, pero en la misma dirección : en el universo oriental de los haikus, Pringles.

5 El gesto y el movimiento del cuerpo y del lenguaje (de la prosodia) de la abuela del Coco son una sola cosa, forman parte de una misma sensación, sentimiento. Por eso y no sólo por la expresión del rostro, el recuerdo de los bunrakus. La escena es una escena japonesa, donde los límites de lo occidental son confundidos : la clasificación de las emociones, la frontera entre el sueño y la vigilia, lo animado y lo inanimado, el significado y el significante, la causa y el efecto, el adentro y el afuera. La praxis poética de Arturo se define como un haiku : el intento por escribir el gesto de señalar eso que sucedió de una vez y para siempre en la memoria del tiempo cotidiano de la infancia. El asombro está ahí ; el sentido de la pérdida aunado al placer, también. De allí que se interese por esa "designación levísima" oriental, frente a la "definición tajante" de Occidente.

6 Arturo ejerce dos variaciones sobre la tradición del haiku. La primera es del orden formal-rítmico : no intentará, nos adelanta, respetar la fijeza estrófica del haiku. Ha de optar, en cambio, por seguir "cierta irregularidad interior (pulsional, personal) que a mi juicio desemboca en eso que llamamos "ritmo"" (Carrera 2013 9) ya que "no deberíamos sostener esas diecisiete sílabas ni el orden cinco-siete-cinco de las mismas sino más bien sonidos, armonías, murmullos, precisiones -de la vista y del oído, del corazón y los pulmones-" (10). En ese ritmo -lo que (nos) acontece, prolongación del momento sagrado de la contemplación, según Yeats, espera de la sorpresa- encontró el vínculo del haiku con la naturaleza, al ser ambos "un subrepticio eco del sentido", y el del poeta con el monje, en la devoción de la transparencia del mundo de un instante. En esta aproximación ético-religiosa que trae en su seno el haiku, en esa constitución del ritmo en tanto médium que trae hasta el aquí ahora algo de otra índole, dimensión o espacio-tiempo, Arturo encuentra, también y además, la salida para la lectura (y escritura) berreta, desconsiderada del trabajo de los haijin, como si fuese una caída del 
lenguaje estructurada en tuits, medida contemporánea de lo rápido y breve o, peor, como si fuese un objeto made in china importado en el mismo aluvión que destruyó a nuestras estaciones. En esta distancia inicial, la de aproximar la observación, la fe y el gesto del poeta a las del monje al tiempo que se pierde la estructura de la tradición para proponer la escritura del ritmo, Carrera recupera la dimensión del gesto, el trazo y la demora de la pintura constitutivas del haiku para intentar responder, por fin, cómo hacer del tiempo particular y sin maldad del haiku el tiempo de la propia vida.

7 Debemos ver en esa recuperación de la praxis ético-religiosa una definición de los principios y alcances de la praxis poética, donde el sujeto se involucra en su tiempo y en el de sus antepasados y contemporáneos, en "cierta abolición del sentido" y en la certeza de que "cada nombre es el depósito de una realidad misteriosa contra la cual no prevalece la experiencia de la nada" (10). En esa dirección, el segundo distanciamiento de la tradición llevado adelante por Arturo se nos aparece como sumamente coherente. Carrera no tradujo directo del japonés sino de las traducciones francesas. En Quiñihual, lugar abandonado por la historia reciente, último límite de la resistencia del cacique Quiñihual frente al cristianismo, espectro de la civilización, pequeña reunión de diez habitantes sólo visitada por el crepúsculo, Arturo Carrera tradujo del idioma de las luces, el francés, los textos canónicos orientales. Doble lectura de la tradición, occidental y oriental, el poeta en su zona lee, relee, escribe y traduce como Borges predijo que debía hacer el escritor argentino, el escritor latinoamericano.

8 Sobre el final de este prólogo-tratado, que ya podría haber sido leído en sus otros ensayos, Carrera cita una interrogación de Yves Bonnefoy:

“ ¿ cuánto deberíamos abandonar de eso que somos, qué colores, qué trazo que vibra de otro modo, qué derrame de claridad sobre la negrura, del sueño en la existencia despierta, para traducir un haiku, traducirlo verdaderamente, no solamente en nuestro pensamiento sino en nuestras vidas ?".

9 En esa interrogación sobre la vida y el haiku podremos encontrar los criterios de selección y disposición de esta antología al mismo tiempo que un nexo directo con toda la obra de Arturo Carrera : el trabajo de traducción no está separado del de la propia escritura ni posee una relevancia menor. Estos Haikus de las cuatro estaciones serán una reedición del Tratado de las sensaciones, ahora un micro-tratado frente a la experiencia del abismo que toda partícula final del haiku nos depara.

10 Micro-universos : micro-utopías. En la confluencia del tiempo del haiku con el tiempo de las estaciones, del año y del paso soñado de la majestuosa ingeniería, en esa dimensión del tiempo y de la pérdida entre lo que pasa, lo que pasó y lo que se perdió y va a seguir perdiéndose, Arturo se detiene brevemente para captar, radar de tormenta, los ritornelos anómalos de la poesía de allá que puede ser, y es, la poesía de acá porque nos toca directamente para formar parte de nuestra memoria, nuestra dicción, nuestro lugar y nuestra vida. Esa es la tarea de la literatura.

11 Arturo, en esta su antología, realiza un movimiento extraño a la tradición del haiku, pero que ya venía siendo necesario : quitándole el predominio y peso a Bashô sobre el haiku, hace de sus discípulos, sus precursores, haciendo de la reunión de haikus y haijins una comunidad diferida y siempre en potencia ${ }^{1}$. Desterrando el discurso de la degeneración del modelo en la copia, de la disolución del autor en sus epígonos, Arturo dota de fuerza a la escritura del haiku y deja flotando en el aire una pregunta vital: ¿ cuál es la voz de un haiku que es todos los haikus? 
12 Los haikus están agrupados en apartados según cada estación. La primera estación es la primavera. Pero, si ni en el Japón ni en Quiñihual es la primera estación del año, ¿ por qué comenzar por la primavera? En Las cuatro estaciones, de modo especular, el primer apartado indica "primavera" entre paréntesis, debajo de "Lartigau", primera de las cuatro estaciones, seguida de Quiñihual (verano), Pringles (otoño) y Krabbe (invierno). Estos haikus son la continuación de aquellos poemas, manifestaciones del tiempo cíclico ininterrumpido de la praxis de Arturo. La primavera, el tiempo utópico por excelencia, el tiempo del re-nacimiento, del pasaje de la muerte a la vida, el tiempo de la pérdida y el derroche, el tiempo de la vida entera, inaugura la lectura que, como sabemos, en Carrera no es sino el trabajo arduo sin embargo feliz de la memoria de la infancia.

13 En la primavera, también, nació Issa, el haijin que inaugura la colección. Y lo hace de modo certero, como si su pluma fuese una estocada en la hoja :

Un mundo de dolor y de pena

aun cuando los cerezos

están en flor ${ }^{2}$

14 Este comienzo en el dolor y la pena, en la revelación taoísta de la vida a través del dolor y la pena en la comunión con el mundo, va a adelantarnos la sensación de encontrarnos no entre un círculo de poetas en todo ajenos a nosotros, sino más bien junto a los parientes literarios de Arturo Carrera, aquellos faunos y faunitos desperdigados en sus textos. Así, la sorpresa se revela en la pretensión de acercarse al niño (Carrera 2013 17) :

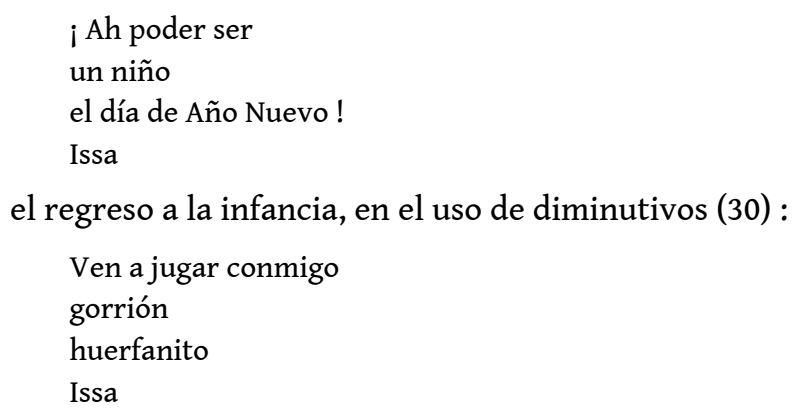

el regreso a la infancia, en el uso de diminutivos (30):

Ven a jugar conmigo

gorrión

huerfanito

Issa

o la confusión de sensaciones y sentimientos del niño perdido y lo natural, en la precisión de la escritura, hermosa simplicidad (65):

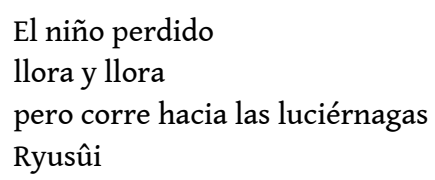

17 Este último haiku pertenece al verano, tiempo del que imaginamos desterrados la soledad y el desasosiego. Esa confusión del niño se inserta, así, en un tiempo amable, haciendo de estos movimientos fuerzas en tensión.

18 Recordemos aquellas Sendas de Oku: en él, los haikus saltan, como ranas, de entre las narraciones de un diario de viajes. Es decir : el haiku forma parte de las anotaciones de la escritura de lo cotidiano, no es un texto autónomo o, mejor dicho, aislado en una página. El haiku muestra la imposibilidad de separar la escritura y la vida del cuerpo, la forma de vivir del arte de vivir. Lo intempestivo del tiempo-en-el-tiempo es recogido en el día a día. Esta praxis es una reeducación de los sentidos y la escritura de la propia vida deviene, así, no una autobiografía sino una otobiographie, una escritura sensual de la vida. El haiku es, por eso, un arte del encuentro : del arte y de la vida, de la escritura 
y del cuerpo, de sus tiempos. El haiku es una praxis vital : escritura de la acción, del cuerpo en la acción, del tiempo en la acción, de la vida en lo cotidiano.

19 Se entiende, así, que el haiku sea un texto político o esté inmerso en una política de vida. Pero a veces quiere mostrarse directamente político (Carrera 2013 88) :

Incluso antes Su Majestad

el espantapájaros no se quita

el sombrero de paja

Dansui

En otro de los haikus encontramos al vespertillo (117):
Bajo el paraguas
vive escondido
el vespertillo
Buson

¿ Será que el vespertillo nos visita desde el francés? ¿ O desde el japonés? Arturo sonríe. Estos haikus bien podrían ser aquellos destellos intencionales que se encuentran en la extensión de su praxis :

Hay una figura en la retórica latina que siempre me intereso : el carmen perpetuum. Imagino que allí hay una profunda modulación del arte de la monotonía. Pero asimismo incluye la excepción de la sorpresa o del sobresalto: una especie de inquietud del sentido y de su revelación, como cuando en Oriente se construye la última partícula de un haiku. Esa línea del poema debe producir el satori o lo que nosotros llamamos la revelación. Todo se alcanza por esa imagen pequeña y vivamente impresa como un fotograma en la mente. El carmen perpetuum prevé una sucesión de estrofas y cada tanto un satori, digamos, una sorpresa agradable y pasajera. $^{3}$

Estas traducciones se sienten, con esto, parte de su trabajo poético, siendo todo él un inmenso carmen perpetuum. Al ir visitando esta colección de pequeños universos poéticos no es sino esa la sensación : la de haber leído ya estos textos como fragmentos de sus movimientos anteriores en su neobarroco de la rotura guiado por la consigna wittgensteniana de arremeter contra los límites del lenguaje, la de reconocer un tono en el habla, la de estar siendo parte del ritmo que mueve y motiva las últimas tareas de Arturo Carrera con la poesía (95).

Pero el agua se escurre

se transforma en la noche

de cada campo

Buson

Campo que es el de Arturo, el de Aira : campo pampeano, pringlense. Podemos imaginar el espacio de la escritura como el espacio monótono del interior de la provincia de Buenos Aires, el espacio pampeano de la ciudad de Pringles, apenas interrumpido, de pronto, por el canto de un grillo, de un animalito, que corta esa modulación. En esa sorpresa el tiempo intempestivo se nos revela: la última partícula del haiku, la voluntad de alcanzar el satori, nuestra iluminación en lo cotidiano. Hay una cierta alegría en esa sorpresa, en esa manifestación del Ritmo. Como niños llenos de "¿por qué ?", los haijin no cesan de interrogar al mundo. Porque ese es uno de los caminos posibles, no deja olvidar el Tao. La búsqueda del satori, y esta vez es Arturo quien nos lo recuerda, no nos excluye : está enraizada en la cotidianeidad de nuestro propio desierto contemporáneo : entre occidente y oriente, el trabajo pringlense de escritura. 


\section{BIBLIOGRAFÍA}

Fuentes :

A. Carrera, Haikus de las cuatro estaciones, Buenos Aires : Interzona, 2013, p. 9

A. Carrera, El Coco, Bahía Blanca : Vox, 2003, p. 31

N. Fernández ; "Diálogo con Arturo Carrera" en Hablar de poesía. Año V, número 9, junio de 2003.

p. 21

\section{NOTAS}

1. Aún así, el texto se cierra con un haiku de Bashô que, como todo maestro, sólo precisa de poco espacio para dibujar el gesto que lo define: "Y ahora / ¡vayamos a contemplar la nieve / hasta caer de agotamiento!".

2. A. Carrera, Op. cit. 2013, p. 15

3. N. Fernández; "Diálogo con Arturo Carrera" en Hablar de poesía. Año V, número 9, junio de 2003. p. 21

\section{AUTORES}

JOAQUÍN CORREA

Universidad Federal de Santa Catarina 